OPEN ACCESS

Edited by:

Stefano Falone,

University of L'Aquila, Italy

Reviewed by:

Georg Bauer,

University of Freiburg, Germany

Olivier Peulen

University of Liège, Belgium

*Correspondence:

Jorgelindo da Veiga Moreira jorgelindo.daveiga@polymtl.ca

TORCID:

Jorgelindo da Veiga Moreira orcid.org/0000-0002-8020-9562

Specialty section:

This article was submitted to

Cancer Metabolism,

a section of the journal

Frontiers in Oncology

Received: 16 June 2020

Accepted: 13 August 2020

Published: 18 September 2020

Citation:

da Veiga Moreira J, Schwartz L and Jolicoeur M (2020) Targeting

Mitochondrial Singlet Oxygen

Dynamics Offers New Perspectives for Effective Metabolic Therapies of

Cancer. Front. Oncol. 10:573399. doi: 10.3389/fonc.2020.573399

\section{Targeting Mitochondrial Singlet Oxygen Dynamics Offers New Perspectives for Effective Metabolic Therapies of Cancer}

\author{
Jorgelindo da Veiga Moreira ${ }^{1 * \dagger}$, Laurent Schwartz ${ }^{2}$ and Mario Jolicoeur ${ }^{1}$ \\ ${ }^{1}$ Research Laboratory in Applied Metabolic Engineering, Department of Chemical Engineering, Polytechnique Montréal, \\ Montréal, QC, Canada, ${ }^{2}$ Assistance Publique des Hôpitaux de Paris, Paris, France
}

The occurrence of mitochondrial respiration has allowed evolution toward more complex and advanced life forms. However, its dysfunction is now also seen as the most probable cause of one of the biggest scourges in human health, cancer. Conventional cancer treatments such as chemotherapy, which mainly focus on disrupting the cell division process, have shown being effective in the attenuation of various cancers but also showing significant limits as well as serious sides effects. Indeed, the idea that cancer is a metabolic disease with mitochondria as the central site of the pathology is now emerging, and we provide here a review supporting this "novel" hypothesis re-actualizing past century Otto Warburg's thoughts. Our conclusion, while integrating literature, is that mitochondrial activity and, in particular, the activity of cytochrome c oxidase, complex IV of the ETC, plays a fundamental role in the effectiveness or non-effectiveness of chemotherapy, immunotherapy and probably radiotherapy treatments. We therefore propose that cancer cells mitochondrial singlet oxygen $\left({ }^{1} \mathrm{O}_{2}\right)$ dynamics may be an efficient target for metabolic therapy development.

\section{Keywords: cancer, mitochondria, singlet oxygen therapy, chemoresistance, metabolic therapy}

\section{INTRODUCTION}

Oxygen is "the molecule that made the world" stated Lane in his seminal book (1). Nowadays, the atmosphere of Earth is composed of $21 \%$ oxygen and used by most organisms for respiration (animals, plants, and many prokaryotes). These living organisms use oxygen as oxidizing agents to retrieve energy from reduced compounds (2).

Human body is made up of 10,000-100,000 billion cells. Every day tens thousands of cancer cells are formed but are also soon eliminated by the immune system (3). The other common point between cancer cells and pathogenic organisms is their dependence on metabolism of healthy cells and the irrigation of nutrients by the blood system to ensure their replication (4). In this way, competition arises between cancer cells and somatic cells for access to nutrients, specially to glucose, and oxygen. This competition is similar to game theory as introduced by John von Neumann (5) then applied to biology by John Maynard Smith (6). Transposed to game theory, the metabolism of healthy cells and cancer cells are distinguished by the way they produce energy in the form of ATP. In presence of oxygen, healthy cells use glucose to produce about 30 molecules of mitochondrial oxidative phosphorylation ATP. Under hypoxic conditions, they produce only 2 molecules of ATP 
through glycolysis and release 2 molecules of lactic acid. As far as cancer cells are concerned, they favor the glycolysis pathway for energy production, even in oxygenated environment, referred as aerobic glycolysis or "Warburg effect" named after the German physician and biochemist Otto Heinrich Warburg who first reported this observation (7-9). Warburg showed that cancer cells in culture have higher rates of glucose consumption and lactate secretion compared to normal cells and hypothesized mitochondrial dysfunction to explain this glycolytic phenotype. However, many more recent studies have demonstrated the integrity of mitochondria in cancer cells $(10,11)$.

Here, we bring an overview of the common therapeutic approaches such as chemotherapy to circumvent tumor progression and limits thereof. We specially focused on the involvement of mitochondria regarding the metabolic adaptation of cancer cells to escape from apoptosis and promote, in some way, cancer recurrence (12). In perspective of this study, we propose that the cancer metabolic phenotype or Warburg effect could be relieved by the controlled generation of mitochondrial singlet oxygen $\left({ }^{1} \mathrm{O}_{2}\right)$. Singlet oxygen is the first excited state of the dioxygen molecule and is part of the ROS species generated during the OXPHOS process. We support the idea that the generation of ${ }^{1} \mathrm{O}_{2}$ in the respiratory chain is a necessary step for OXPHOS and ATP production. Our hypothesis is that the mitochondrial accumulation of ROS observed during phases of high energy demand or in periods of substrates deficiency would be due to a limitation of the respiratory capacity of cells in general, and in particular in tumors where physical and metabolic variabilities have been reported (13). This, is a fundamental review deciphering on how cancer cells' ROS production is an adaptation to escape apoptosis and how strategies such as singlet oxygen-oriented therapy could potentially counteract cell proliferation and metastasis.

\section{MITOCHONDRIAL RESPIRATION IS THE KEY TO UNDERSTAND CANCER METABOLISM}

The cell cycle is also a metabolic cycle regulated by redox transitions promoting fermentation or cellular respiration (14). Cancerous masses deploy a panoply of adaptative actions in the face of external stresses such as chemotherapy. This is partly made possible by the "hijacking" of the genetic program for regulating the cell cycle. In the following, we will thus first describe the mitochondrial metabolism and the electron transfer chain (ETC) functioning. Then we will decipher how cancer cells manage to "hijack" mitochondrial activity in its favor and to escape from apoptosis even under ROS-induced chemotherapy treatments.

\section{Energetic Metabolism and the Respiratory Chain}

Mitochondria are involved in various cellular processes such as differentiation and cell death (apoptosis) as well as supporting the immune response $(15,16)$. The mitochondria are the energy factories in eukaryotes. They mobilize the enzymes necessary for the proper functioning of the citric acid cycle (TCA, or Krebs cycle) and are involved in the management of the redox balance. Mitochondria use oxygen to extract energy from carbonbased nutrients found in the cellular environment or stored as intracellular macromolecules like glycogen and results in the synthesis/recycling of adenosine triphosphate (ATP) by phosphorylation of adenosine diphosphate (ADP). This process called oxidative phosphorylation (OxPhos) takes place at the level of the mitochondrial ETC chain.

\section{The "Classical" Respiratory Chain of Eukaryotic Cells}

Peter D. Mitchell proposed in 1961 the chemiosmotic theory to explain the synthesis of ATP by OxPhos mechanism. This theory suggests that the production of ATP is made possible by a proton gradient $(\Delta \mathrm{pH})$ formed on either sides of the inner membrane of the mitochondria thanks to an ATPase catalyzing the reaction (17). The proteins animating this respiratory chain promote the creation of this $\triangle \mathrm{pH}$ thanks to the energy of the redox couples $\left(\mathrm{NAD}^{+} / \mathrm{NADH}\right.$ and $\left.\mathrm{FAD} / \mathrm{FADH}_{2}\right)$ present in the mitochondrial matrix and brought about by the catabolism of carbon-based resources. ATPase takes advantage of this electrochemical gradient also called protonmotive force $(\Delta \mathrm{p})$ for the phosphorylation of ADP into ATP. The ETC of eukaryotic cells is essentially composed of enzymes and coenzymes involved in the transfer of electrons and the synthesis of ATP. Four protein complexes (CI-IV) are involved in electron transport and oxygen reduction. ATP synthase, also known as complex V (CV), catalyzes ATP synthesis (Figure 1) (1801). A special focus is placed on complex IV (IV) or cytochrome c oxidase, since this enzyme has a pivotal role in mitochondrial respiration. It catalyzes the transfer of electrons from the reduced form of cytochrome $\mathrm{c}$ to dioxygen, which becomes the final acceptor of electrons in the respiratory chain $(19,20)$. Two molecules of water are formed through this reaction and four protons are pumped to the intermembrane space. This enzyme has been well-studied, in particular for understanding the mechanisms allowing both the reduction of dioxygen into water molecules and the flow of protons through the protein structure (21). The pivotal role of prosthetic (22) groups has been demonstrated. These metallic prosthetic groups form two copper redox centers $(\mathrm{CuA}$ and $\mathrm{CuB})$ and two heme centers (heme $a$ and heme $a_{3}$ ). CuB and heme a3 are physically close and form a bi-nuclear center where the oxidation of oxygen takes place. $\mathrm{CuA}$ is the first electron acceptor of cytochrome $\mathrm{c}$ while heme a serves as an intermediary for the transfer of electrons between $\mathrm{CuA}$ and the binuclear center for the reduction of $\mathrm{O}_{2}$ (18). A detailed model of the $\mathrm{O}_{2}$ activation and its reduction cycle has been proposed $(23,24)$.

\section{Regulated Steps of Mitochondrial Respiration}

The desire to identify a major OXPHOS "controller" began in the 70-80s (25), notably thanks to contributions of the Metabolic Control Theory (MCT) (26-28). CIV, CV, and the mitochondrial ATP/ADP translocase were the main candidates 


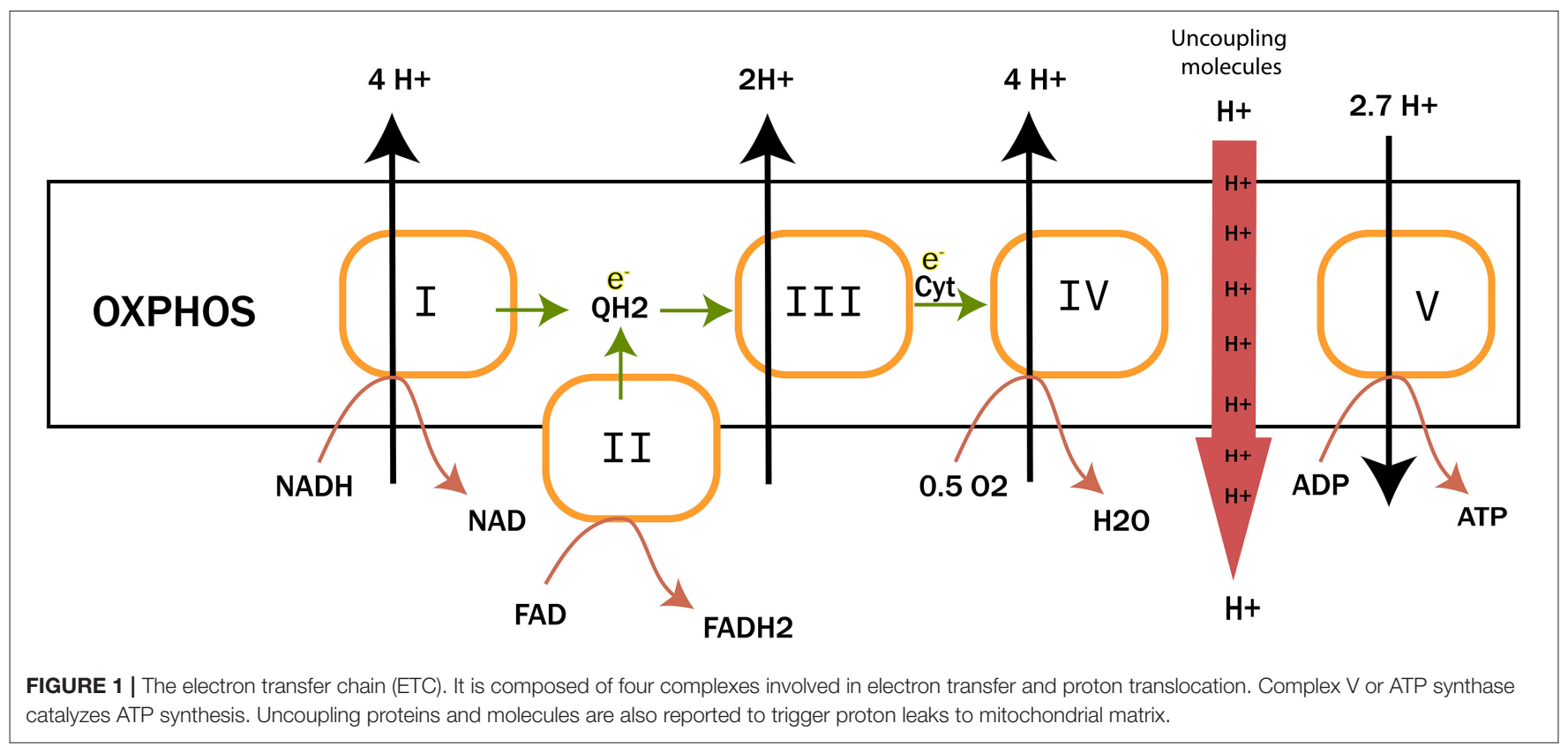

$(29,30)$. Subsequently, work on mitochondria isolated from liver cells has highlighted the role of these proteins, depending on the energy state of the cell (29). In short, during highly active OxPhos phase, the supply of electrons from substrates and the electron flux through the ETC were estimated as the limiting steps. During the stationary phase of respiration, proton translocation through mitochondrial membrane was the limiting step. Finally, when the cell's energy demand is reduced, the activity of ATP translocase became the limiting factor for OxPhos.

\section{The Potential Role of Apoproteins in Mitochondrial Mode Switch}

ETC complexes behave like real biological capacitors, by analogy with electrical circuits. They have the capacity to store the electrons recovered from NADH or succinate. In 1964, John Rieske isolated a subunit of Complex III. He highlighted the presence of an iron-sulfur atomic aggregate on this apoprotein (31). This component of complex III has since become the Rieske protein while other proteins have been identified and assimilated to the Rieske protein due to the presence of the iron-sulfur cluster [Fe-S]. This is the case for complexes I and II of the respiratory chain $(32,33)$ but also for aconitase $(34)$ which also consist of one or more several centers [Fe-S]. One may wonder if inhibition of these clusters could impair cellular respiration. Few studies have been devoted to this problem. Graham and Trumpowe (35) carried out mutations in the conserved domains of the Rieske protein in the yeast Saccharomyces cerevisiae. They observed that directed-mutations on codons of amino acids known to interact specifically with the $[2 \mathrm{Fe}-2 \mathrm{~S}]$ cluster and present exclusively in aerobic organisms lead to an inability of these mutants to use non-fermentable carbon sources for their growth (35). As described above, this prosthetic group, which is also present in cytochrome $b c 1$ (complex III) is the first electron acceptor emitted by ubiquinol (Q) and participates in the creation of the protonmotive force. Other studies emphasize the importance of the $[2 \mathrm{Fe}-2 \mathrm{~S}]$ cluster in maintaining OxPhos. Diaz et al. (36) have notably demonstrated that mutations on the gene coding for Rieske protein in fibroblasts causes a decrease in the synthesis of complexes I and IV and OxPhos deficiency (36). These [Fe-S] clusters are not the only prosthetic groups to play a major role in mitochondrial respiration. The copper $(\mathrm{CuA}$ and $\mathrm{CuB})$ and heme centers of the CIV, involved in electron transfer and $\mathrm{O}_{2}$ activation reduction $(24,37)$, have a pivotal role in maintaining the activity of the other complexes of the ETC (38). Likewise, it has been recently demonstrated that the activity of CIV is regulated by Hypoxia-induced Factor (HIF) proteins in yeasts and animal cells $(39,40)$. Interestingly, these proteins which belong to the HIF family, do not regulate the expression of CIV specifically but rather the formation of supercomplexes or respirasomes $(41,42)$. Importantly, HIF proteins are well-known to play an important role in the metabolic reprogramming, evading immune surveillance and resisting death of cancer cells (43-45). HIF-1 signaling pathway allow cancer cells to adapt to the use of a particular substrate or to adapt to environmental stresses by optimizing the flow of electrons through ETC and escape programmed cell death $(43,45,46)$.

\section{CURRENT CANCER TREATMENTS: EFFICIENCY AND LIMITS}

Biochemical approaches to the management of cancer patients represent most treatments. They mainly include chemotherapy. However, in recent years immunotherapy treatments have become popularized, as well as metabolic therapy but to a lesser extent. 


\section{Chemotherapy}

Standard chemotherapy protocols for cancer combine therapeutic agents that induce DNA damage with another agent, usually from the taxane class, that inhibits microtubule dynamics $(47,48)$. An anti-angiogenic agent targeting neotumor vessels may be combined depending on the case. These chemotherapeutic agents are inoculated intravenously (IV). Intraperitoneal (IP) chemotherapy can also be used to deliver higher doses of chemotherapeutic agents to the peritoneal cavity, the metastatic site for ovarian cancer, for example. The main chemotherapeutic agents offered to patients are platinum salts, especially cisplatin. They belong to the class of alkylating compounds. They cause the proliferation of cells to stop after binding to DNA. The cytotoxic potential of cisplatin was incidentally discovered in 1965 by B. Rosenberg et al. When they applied an electric field from platinum electrodes to a culture of Escherichia coli bacteria, they noticed that cell division had stopped (49). They demonstrated that the inhibition of cell divisions was due to the formation of a complex between the platinum produced by the electrodes and the ammonium chloride in the medium. Since then, several platinum complexes have been tested to analyze their cytotoxic effect. Cis-dichlorodiamino-platinum (II), or CDDP, is the compound with the most pronounced effects (50).

CDDP is a molecule made up of a central platinum atom, of two labile chlorine atoms in the cis position and two inert ammonia groups (Figure 2). Rosenberg and VanCamp showed that the CDDP presented a significant anti-tumor activity in mice having developed sarcomas and leukemias (51). Subsequently, human clinical trials have shown the effectiveness of CDDP-based treatments for testicular cancer (52). Its use as an anti-tumor compound was validated by the FDA (Food and Drug Administration) in 1978. More than 35 years later, the CDDP remains the most used drug in the treatment of ovarian cancer. The CDDP enters the cell by passive diffusion, facilitated via copper or active transporters $(53,54)$. In the cytosol, the chloride ions $\left(\mathrm{Cl}^{-}\right)$of the CDDP are substituted by hydroxyl groups $(\cdot \mathrm{OH})$ (Figure 2). At physiological $\mathrm{pH}$, these electrophilic complexes react with nucleophilic sites such as the nitrogenous bases of the DNA molecule. However, only $5-10 \%$ of the total concentration of intracellular CDDP are found in the nucleus. The remaining CDDP fraction binds to RNAs, proteins, or glutathione (55). In the event that DNA damage becomes permanent, the signaling pathways that lead to cell death are activated (56). Thus, the ability of cells to make repairs following DNA damage caused by CDDP modulates their sensitivity to treatments. Cisplatin is the first platinum derivative to be used in chemotherapy. However, its high toxicity limits its use (nephrotoxicity, neurotoxicity, ototoxicity). Three analogs can be used in chemotherapy: carboplatin, oxaliplatin, and nedaplatin. Often combined with platinum salts (cisplatin or carboplatin) for the treatment of ovarian cancer, taxanes (paclitaxel or docetaxel) are natural alkaloid diterpenes extracted from bark or yew needles $(57,58)$. Taxanes exert their cytotoxic effect by binding to microtubules in the cell cycle and inhibit cell division by preventing depolymerization of microtubules during G2/M phase (before mitosis) $(59,60)$. On the other hand, weekly administration of paclitaxel has been shown to induce cell death independent of microtubule stabilization. The transcription of different genes involved in repairing DNA damage, inflammation, or cell proliferation is, in fact, also modulated. In addition, several apoptotic or oxidative stress signaling pathways are also activated in response to paclitaxel. All these strategies are applied to potentiate the anti-cancer activity of paclitaxel.

\section{Immunotherapy}

Recently, anti-angiogenic agents have been introduced into ovarian cancer treatment protocols. They target the formation of new vessels from preexisting vessels (angiogenesis), a process necessary for tumor survival and spread. Bevacizumab (Avastin ${ }^{\circledR}$ ) is a monoclonal antibody that binds to the proangiogenic factor VEGF (Vascular Epidermal Growth Factor) and prevents its interaction with its receptors located on the surface of endothelial cells (61). In parallel, many clinical trials aim to use small inhibitory pharmacological molecules targeting the processes involved in tumor growth and/or spread (antibodies, inhibitors). Special mention of antibodies directed against pro-angiogenic factors (anti-VEGF antibodies), molecules blocking DNA repair systems (PARP inhibitor) or also inhibitors of folate receptors, the latter being overexpressed by ovarian cancer cells. Molecules that interfere with altered signaling pathways in ovarian cancer are also developed. They target the MAP-Kinases, PI3-Kinase/Akt pathways or integrintype adhesion receptors. Immunotherapy strategies are also being considered (antibodies, inhibitors of immunological checkpoints, vaccines) (Figure 3). All these trials open up new therapeutic perspectives with the hope of seeing new molecules coming to the market for the treatment of ovarian or other type of cancer such as glioblastoma multiforme (GBM) (62).

\section{CANCER RECURRENCE: THE SPECIAL CASE OF GBM AND OVARIAN CANCER}

In the case of ovarian cancer, $70-80 \%$ of patients respond well to initial treatments. However, more than $80 \%$ of patients relapse within the next 6-36 months. Second line treatments include a cytoreductive surgery combined with chemotherapy (63). Second-line treatments aim to improve the quality of life of patients and increase the progression-free survival of the disease. In the absence of effective therapies, most recurrent ovarian cancers are incurable. This is likely due to phenotypic plasticity and adaptation, a process common to cancer cells $(64,65)$. During the recurrence process, ovarian cancer cells acquire an adaptive phenotype allowing them to overcome the mechanisms guarantying cell and tissue homeostasis. These characteristics were identified in 2000 and supplemented in 2011 by Hanahan and Weinberg $(66,67)$. These characteristics are: (i) self-sufficiency in proliferative signals (ii) insensitivity to growth inhibition signals, (iii) ability to replicate indefinitely, (iv) genomic instability, (v) angiogenic induction potential, (vi) an 


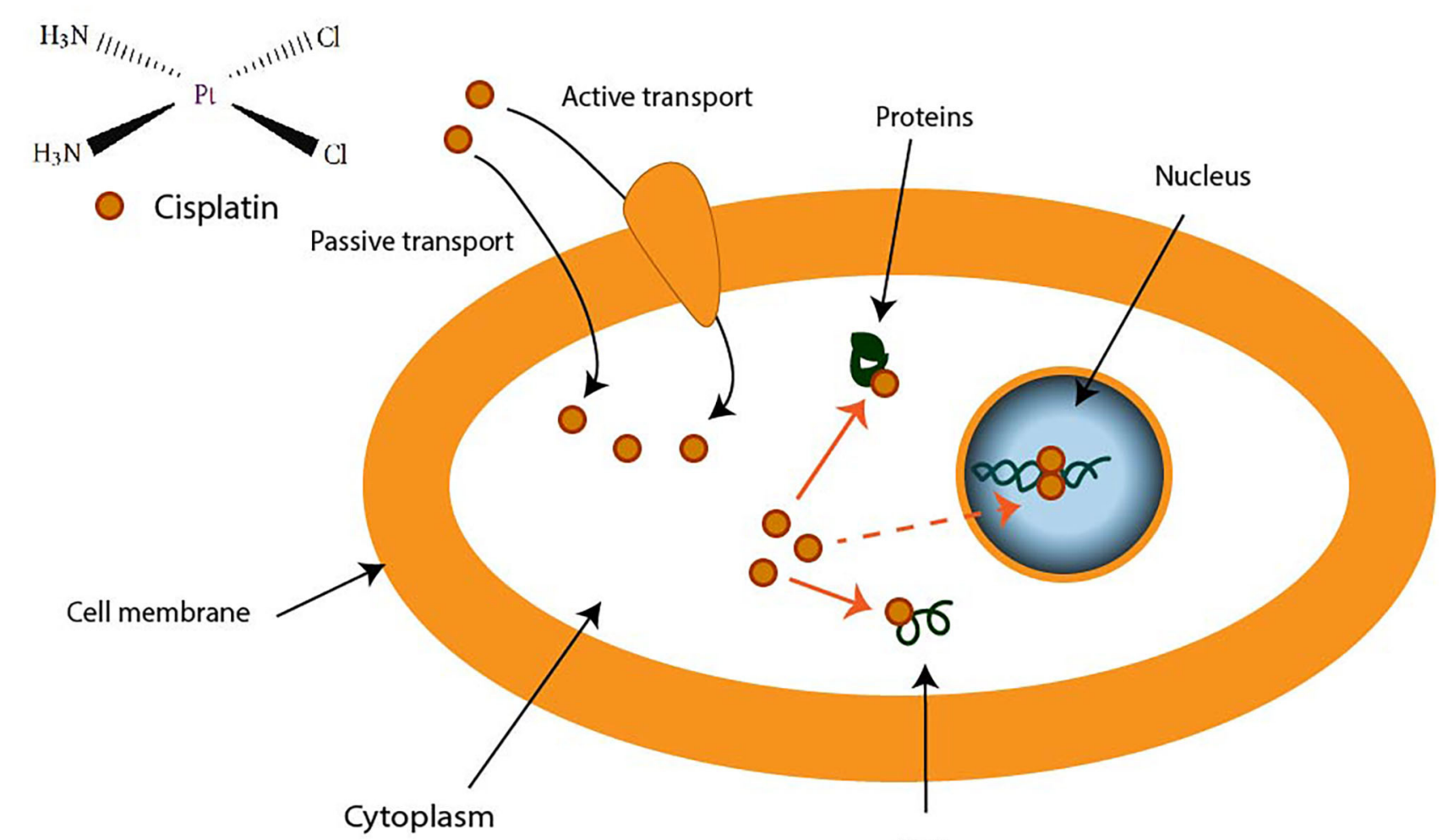

RNA

FIGURE 2 | Transport of cisplatin to intracellular medium. Cisplatin crosses cell membrane by passive diffusion and by active transport. It binds to DNA, RNA, and some proteins.

ability to invade tissues and form metastases, (vii) a misregulation of cellular energy metabolism, (viii) an ability to escape the immune system and to promote an inflammatory environment, and (ix) the ability to resist cell death. This constitutes a major obstacle in the therapeutic management of cancers. Taken all the above, a special focus need being placed on points (I and II), and to decipher signaling pathways that could explain the phenotypic variability within a tumor mass leading to resistance to programmed cell death.

\section{Chemoresistance of Ovarian Cancers}

Chemoresistance is defined as the ability of cancer cells to survive the cytotoxic effect of anticancer agents. It can manifest itself right away, i.e., intrinsic chemoresistance. In other cases, the treatments make it possible to obtain a partial or incomplete response, which then become ineffective over time. This is defined as acquired chemoresistance. Loss of sensitivity of ovarian cancer cells to platinum-based treatments is one of the major complications of ovarian cancer. The mechanisms leading to the appearance of this chemoresistance have been classified in four categories according to the moment when they intervene in the response chain of the CDDP (68). Two mechanisms promote the inhibition of the cytotoxic effect of CDDP before its interaction with DNA. A decrease in the concentration of intracellular CDDP is observed following an inhibition of facilitated diffusion by the copper transporter or an increase in its efflux by ABC-type transporters (ATP Binding Cassette). For example, overexpression of ATP7A (a member of the ABC protein family) is associated with a poor prognosis (69). An increase in the sequestration of CDDP by thiols intracellular occurs. Indeed, glutathione (GSH) can react with CDDP thus forming a platinumGSH complex which will be subsequently eliminated. $\gamma$ Glutamylcyteine synthetase, the enzyme responsible for the synthesis of GSH, has been shown to be overexpressed in ovarian cancers (70-72).

\section{Chemoresistance of Glioblastoma Multiforme}

It is generally accepted that cancer cells produce large amounts of ROS, mainly in the inner mitochondrial membrane (IMM), the site of cellular respiration (73). When the flow of electrons is slowed down at the level of the electron transfer chain (ETC), this produces mitochondrial ROS (mtROS) species such as superoxide radical $\left(\mathrm{O}_{2} \cdot{ }^{-}\right)$, hydrogen peroxide $\left(\mathrm{H}_{2} \mathrm{O}_{2}\right)$ or hydroxyl radical $(\cdot \mathrm{OH})$. These reactive species can, in the long run, lead uncontrolled oxidations of mitochondrial DNA (mtDNA), lipids and proteins. Interestingly, cancer cells have been shown to decrease the generation of mitochondrial ROS by improving their mitochondria coupling (74). This phenomenon 


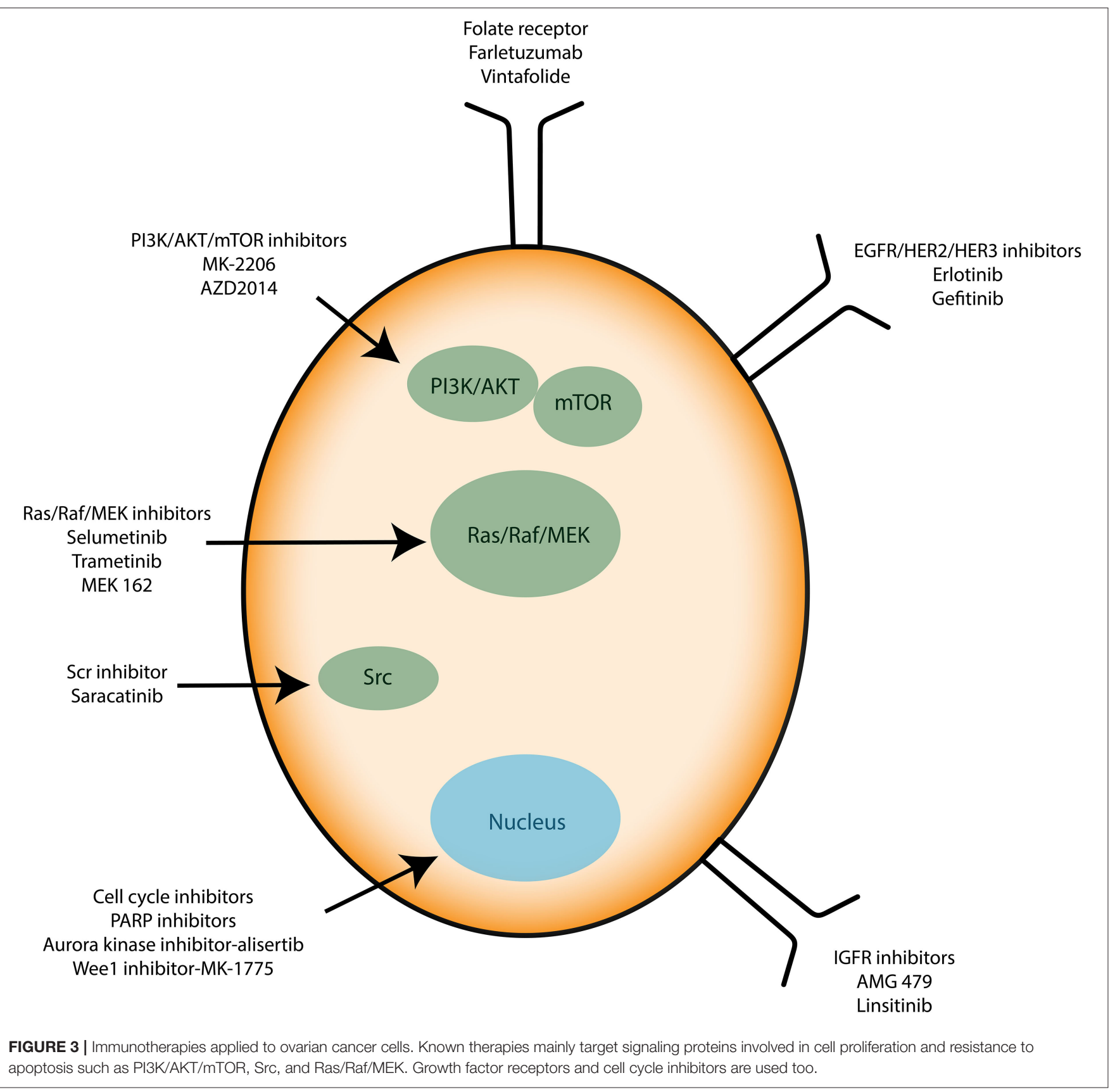

even occurs when external ROS generation methods are applied. This is the case of glioblastoma multiforme (GBM) cells resistant to Temozolomide (TMZ), a chemotherapy drug commonly used for treating gliomas (75). Recent studies have demonstrated that the resistance of glioma cells to drugs are acquired characteristics that are linked to mitochondrial activity in general, and to the activity of complexes (I-IV) of the electron transfer chain in particular (13, 74-76). Oliva et al. (75) studied chemoresistance in a glioma cell line and xenograft using TMZ chemotherapy agent. They managed to show that TMZ-resistant cells have a better management of mtROS generation due to a higher mitochondrial coupling. Moreover, the chemoresistant glioma cell line showed reduced mtROS production concomitant with increased oxygen consumption, and lowered proton leak. Interestingly, the authors showed that TMZ-resistant cells consumed less glucose and produced less lactate which are markers of reduced Warburg effect (Figure 4). Finally, the authors managed to reserve TMZ resistance and increased sensitivity to chemotherapy by treating glioma cells with the oxidant L-buthionine-S,R-sulfoximine. On the other hand, the antioxidant $\mathrm{N}$-acetyl-cysteine treatment prevented TMZ cytotoxicity in sensitive cell lines by vanishing TMZ-dependent 
mtROS generation (75). These observations show the pivotal role of mtROS in the induction of pro and antitumor signaling pathways (74).

TMZ triggers mtDNA alterations and creates local mtROS accumulation. Then, proteins and lipids are at the mercy of mtROS, which trigger its oxidation and compromise mitochondrial membrane integrity. Therefore, mtROS seems to have a feed-forward loop effect on mtDNA. Indeed, it has been reported that minor mtDNA alterations and mutations are major contributors to mtROS accumulation in cancer cells (77). Exactly 13 ETC proteins are encoded in mtDNA and the rest are nuclear genome encoded (78). Mutations in the genes encoding these subunits cause ETC dysfunction and accumulation of mtROS $(74,79)$. Interestingly, Oliva et al. (75) also reported a sharp drop of TMZ-induced ROS generation in mitochondrial DNAdepleted $\left(\rho^{\circ}\right)$ glioma cell line and decreased cell sensitivity to TMZ drug. Sensitivity of the glioma cell line to TMZ was restored upon repopulating cell with functioning mitochondria. As we postulated above, mitochondrial metabolism and its integrity appear to play a pivotal role in the treatment of cancer and recurrences that may occur.

\section{METABOLIC THERAPIES FOR CANCER TREATMENT}

One of the most studied pathology related to mitochondrial metabolism is cancer. First studies date from the 1920s in which Otto Heinrich Warburg, future Nobel Prize of medicine winner in 1931, observes that cancer cells produce abnormally high amounts of lactate, even in oxygen aerated environment $(9,71$, 80). He explained that cancer cells derive their energy mainly from the fermentation of glucose or aerobic glycolysis. Warburg later hypothesized that the fermentative phenotype of cancer cells was due to dysfunction of the mitochondria (8). Our recent works has helped into validation of some Warburg's assumptions. Indeed, we have demonstrated that human and mouse cancer cell lines have very low mitochondrial membrane potential $(\Delta \Psi \mathrm{m})$ and more pronounced glycolysis compared to the respective healthy cells (81). We also proposed complementary therapeutic approaches to chemotherapy, aiming to counteract the Warburg effect in cancer cells $(34,82-84)$. These are METABLOC, a combination of small molecules composed of $\alpha$-lipoic acid, pushing carbon flux to mitochondria, and hydroxycitrate, an inhibitor of lipogenesis.

\section{Cancer Cells Have a Reduced Mitochondria Horsepower}

Cancer cell growth is promoted by the anabolic signaling pathways and sustained metabolic reprogramming $(45,85,86)$. We sought to establish the metabolic profile of cancer cells based on the characterization of physico-chemical parameters in healthy and cancerous primary cells isolated from the colon in patients. For each of the two populations, cells were separated by elutriation and then collected in different phases of the cell cycle (G0/G1/S/G2/M) according to their sizes. The parameters studied are the redox potential of the cells by quantification of the
$\mathrm{NA}(\mathrm{D}) / \mathrm{NAD}(\mathrm{P}) \mathrm{H}$ species, the energetic state of the cells by ATP assay and the intracellular $\mathrm{pH}(\mathrm{pHi})$, which could be associated with the metabolic activity. The results confirm the two major phenomena associated with cancer cells: the metabolic activity is more pronounced compared to healthy cells, which results in a more alkaline $\mathrm{pHi}$ (81). Indeed, cancer populations in G0 have, on average, a pHi of $7.29 \pm 0.13$ while the $\mathrm{pHi}$ of healthy cells in the same phase of the cycle is $6.87 \pm 0.10$. We have also reported a lower energy efficiency in the cancer population. This is characterized by a lower amount of ATP (2X less in $\left.\mathrm{G}_{0}\right)$. The $\mathrm{NAD}^{+} / \mathrm{NADH}$ and $\mathrm{NADP}^{+} / \mathrm{NADPH}$ redox ratios are up to $5 \mathrm{X}$ and 10X higher, respectively, in cancer cells. It also reflects a more pronounced glycolytic flow as hypothesized by Warburg, while the production of lactate in the culture medium has not been determined. Indeed, a higher $\mathrm{NAD}^{+} / \mathrm{NADH}$ ratio is necessary for the maintenance of glycolysis while the production of lactate ensures the turnover of $\mathrm{NAD}^{+}$by lactate dehydrogenase (LDH). Likewise, $\mathrm{NADP}^{+} / \mathrm{NADPH}$ conditions entry into the pentose phosphate pathway (PPP) and generates the NADPH necessary for the synthesis of fatty acids and of other membrane lipids. These results were then confirmed in various mice and human cell lines. In addition, $\Delta \Psi \mathrm{m}$ has been quantified in healthy and cancerous cell lines. The results show that the mitochondrial membrane potential is significantly lower in cancer lines. This lower $\Delta \Psi \mathrm{m}$ in cancer cells is assumed, such as lower energy efficiency (ATP synthesis), even when higher glycolytic flux is found in cancer cell population. Therefore, these results partially confirm Warburg's observations and offer avenues for therapeutic innovations.

\section{Metabolic Therapies Targeting Tumor Growth}

In our last experimental study, we followed tumor growth in mice to which tumors were grafted and subjected to metabolic treatments for 59 days (84). The molecules used part of the METABLOC, supplemented with other molecules known from the pharmacopeia. These are $\alpha$-lipoic acid ( $\alpha$-LA) and hydroxycitrate (HCA), both used as food supplements. The $\alpha-$ LA is an inhibitor of pyruvate dehydrogenase kinase-2 (PDK2), reported as inhibitor of pyruvate dehydrogenase $(\mathrm{PDH})$ in normal cells but to a greater extent in cancer cell $(85,87,88)$ (Figure 5). Interestingly, a recent study also reported effective inhibition of angiogenesis and HIF1- $\alpha$ activity in mice tumor xenograft under dichloroacetate (DCA) treatment (89), known as a major inhibitor of PDK2 (90). Moreover, PDK2 gene disruption in lung cancer cells have been reported to increase cell sensitivity to Paclitaxel chemotherapeutic agent (91). Part of METABLOC, HCA is an inhibitor of ATP-citrate lyase (ACL) to prevent lipogenesis $(82,92,93)$. Finally, we used metformin, which is used in type II diabetes (94) and reported as inhibitor of complex I (95-97), and diclofenac, which is an anti-inflammatory and inhibitor of lactate dehydrogenase $(\mathrm{LDH})$ and of the transporter of monocarboxylate (MCT1) $(98,99)$. A positive control group of mice was treated with cisplatin, a classic chemotherapeutic agent. We reported that the combination of these four molecules has an inhibitory effect on the growth of the tumor implanted 


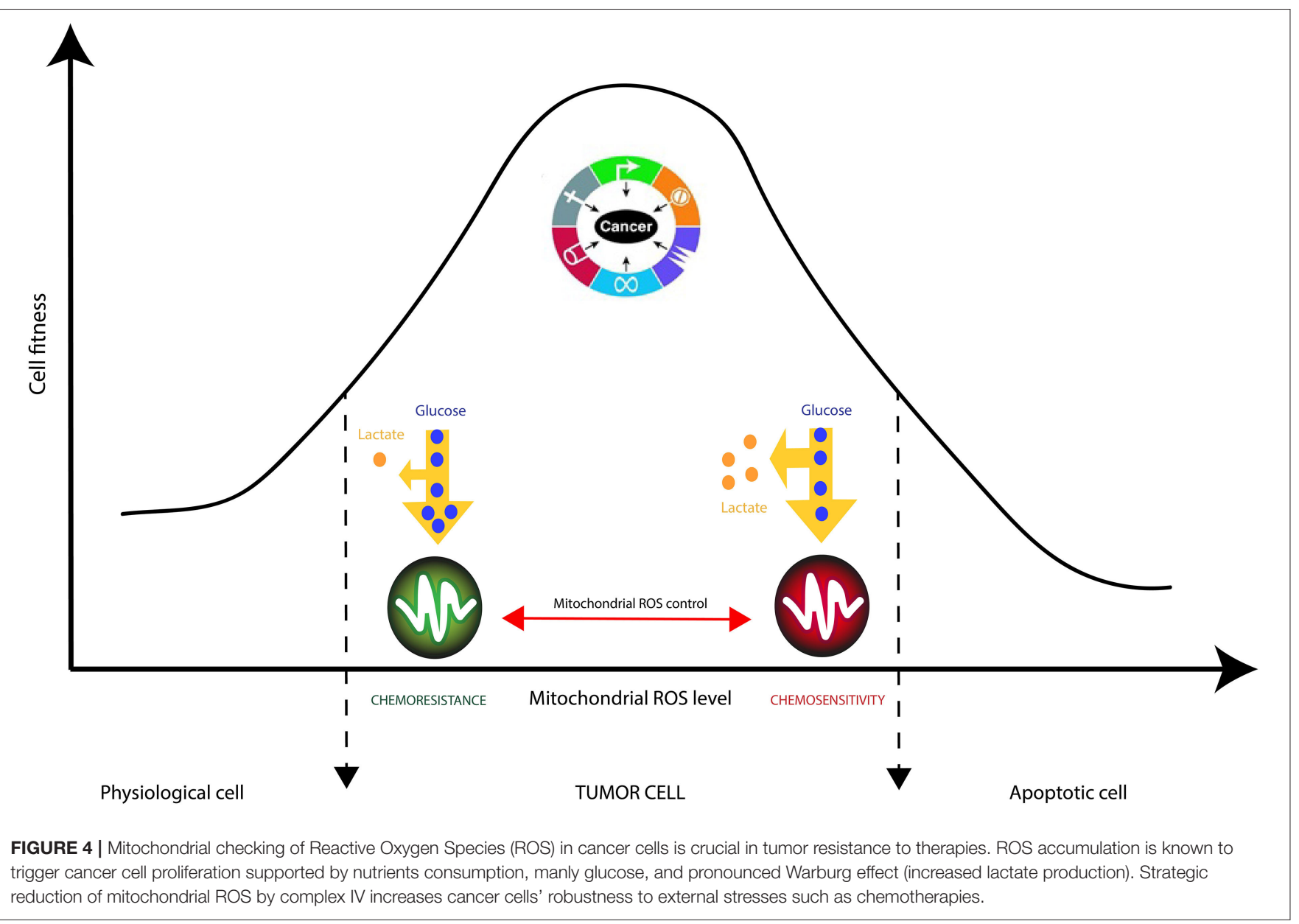

in mice (84). Indeed, when the molecules are used separately, there are no major effects compared to the control group without treatment. However, when metformin is applied in high doses combined with $\alpha$-LA and HCA, the growth of the tumor is clearly slowed down and then inhibited after $\sim 50$ days of followup. The inhibition is even more pronounced when high-dose diclofenac is added in combination with METABLOC and highdose metformin.

In parallel with this experimental work, we have developed a kinetic model of central metabolism to simulate tumor growth and predict the effect of previous molecules on intracellular energy flows. This model includes a reduced and simplified metabolic network of cancer cell metabolism and manages to simulate tumor growth but also the inhibitory effect of the metabolic therapy. Simulations show a reverse Warburg effect under the action of metabolic therapy. This is evidenced by a net flow of blood lactate re-consumption through $\mathrm{LDH}$ and increased mitochondrial respiration, a characteristic phenotype of healthy cells. These experimental results show that it is possible to perturb the metabolic stability of cancer cells and restore a basal metabolism close to that of healthy cells. Mitochondrial metabolism in general, and cell respiration through the electron transfer chain in particular, therefore seems to be the ideal target to make tumor masses more vulnerable to treatments and for inducing apoptosis or necrosis of the tumor mass (84).

\section{PERSPECTIVE: OVER-ACTIVATING CANCER CELLS MITOCHONDRIA BY SINGLET OXYGEN-ORIENTED PHOTODYNAMIC THERAPY}

As summarized in the previous sections, the synthesis of ATP by OXPHOS is made possible thanks to the successive transfers of electrons through the electron transfer chain (ETC) (Figure 1). Misregulation on one of these ETC complexes often causes metabolic disorders ranging from transient paralysis to prolonged degenerative processes such as myopathies, Alzheimer's, cancer, and other acquired degenerations (41). In the case of cancer, we have reported works showing the strict regulations of these complexes as well as the strategies adopted by cancer cells to escape from the immune system regulation. We bring here a new explanation, under strong assumptions, on the "mitochondrial dysfunctions" observed in certain sub-populations of cells as well as therapeutic solutions 


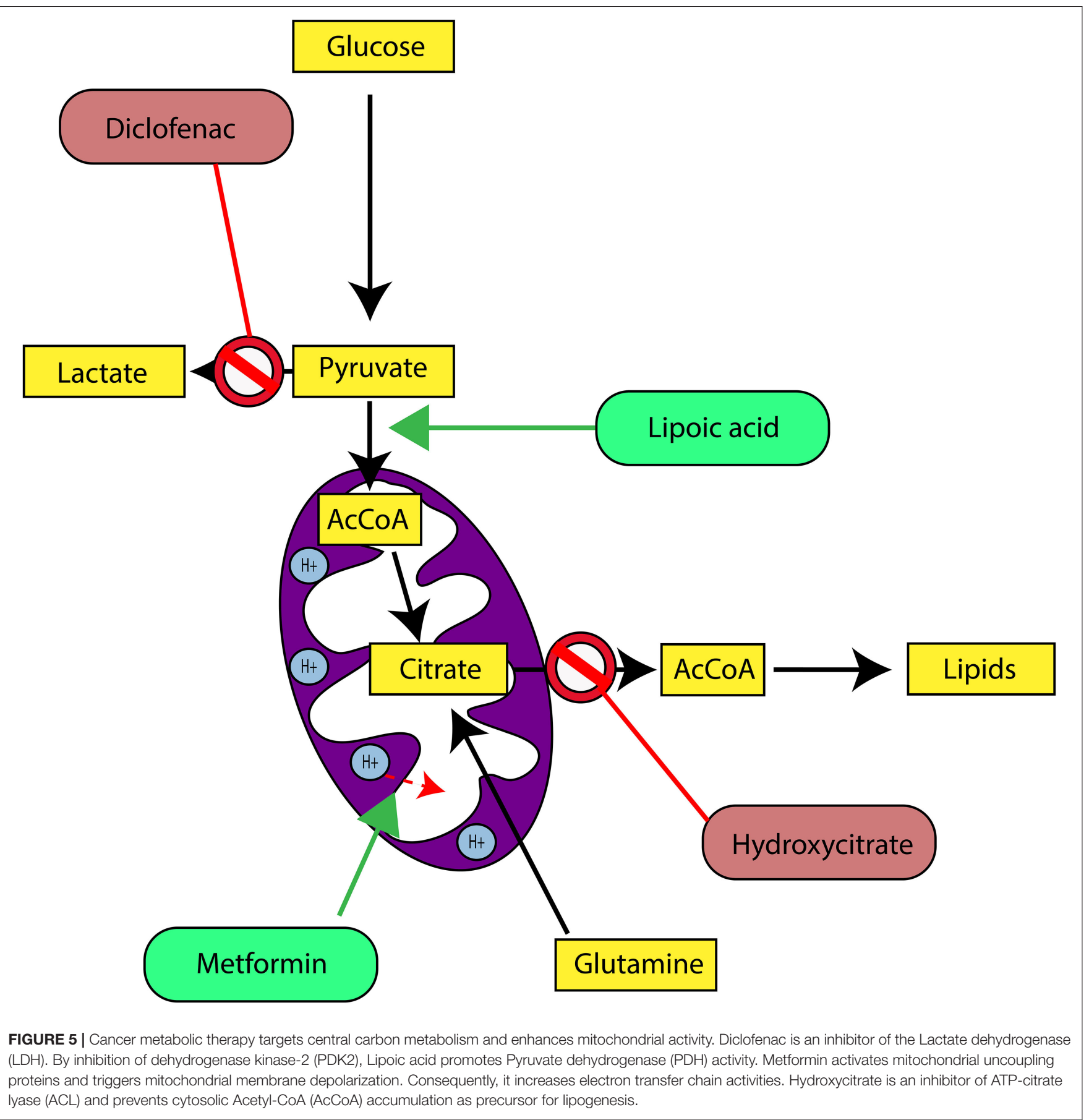

which could reverse the degenerative process linked to the proliferation and metastasis of most of tumor cells.

We propose that saturation of ETC with electrons could be the cause of the glycolytic phenotype of cancer cells but also of the accumulation of deleterious oxidizing species, such as ROS, also present in neurodegenerative pathologies (Alzheimer, Parkinson, Huntington). This electrochemical engorgement of the respiratory chain can as well be explained by the inhibition of complexes of the ETC which would prevent the transit of the electrons and by a modification of the physicochemical nature of oxygen (the final acceptor of the electrons in the ETC). Thus, cancer cells carry out a metabolic reprogramming to reach out a new metabolic steady state characterized by rapid proliferation and pronounced glycolysis, a specific phenotype described by DeBerardinis and Chandel (7) and Warburg (8). Our undisclosed preliminary results support the hypothesis of a modification of the energetic state of intracellular oxygen to explain an overvoltage at the "limits" of ETC. 


\section{Oxygen Activation in Biological Systems}

Despites its high thermodynamic reactivity, dioxygen reacts slowly with most organic molecules because of spin restriction. Its stable state corresponds to a triplet electronic ground state, referred as triplet oxygen $\left({ }^{3} \mathrm{O}_{2}\right)$. The stable ${ }^{3} \mathrm{O}_{2}$ has two unpaired electrons occupying the $\pi$ molecular orbitals with the same spin orientation (Figure 6A). This prevents its spontaneous combustion with molecules having paired electrons (100). On the other hand, $\mathrm{O}_{2}$ can turn highly reactive with an input of energy and electronic excitation of the ground state ${ }^{3} \mathrm{O}_{2}$. This excited state is referred as singlet oxygen $\left({ }^{1} \mathrm{O}_{2}\right)$ in which the electrons of the $\pi$ orbitals are paired with opposite spin. This allows ${ }^{1} \mathrm{O}_{2}$ to be much more reactive with organic molecules (101) (Figure 6A).

Generation of ${ }^{1} \mathrm{O}_{2}$ from water molecule have been widely reported during photosynthesis in plants and cyanobacteria, using energy from the sunlight (102). In these systems, singlet oxygen is produced by light absorption by the photosensitizers. It is especially the case in plants where ${ }^{1} \mathrm{O}_{2}$ is generated by the chlorophylls and other cofactors of the photosystem II (103). Once the highly reactive ${ }^{1} \mathrm{O}_{2}$ is produced, it can be deactivated by quenching molecules such as beta-carotene, alpha-tocopherol, or plastoquinone. Cytochrome complex has also been involved in ${ }^{1} \mathrm{O}_{2}$ production in plant (104). The authors showed that photoactivation of isolated cytochrome b6f complex triggers ${ }^{1} \mathrm{O}_{2}$ generation. More precisely, it was shown the Rieske Fe$\mathrm{S}$ protein-like cytochrome b6f center is the cluster involved in ${ }^{1} \mathrm{O}_{2}$ production (31). Taken together, these observations raise the question of a possible involvement of singlet oxygen in mitochondrial respiration.

The eukaryotic respiratory chain has been extensively studied. As depicted in previous sections, it is essentially composed of five protein complexes involved in electron transfer, proton pumping across the mitochondrial membrane, oxygen reduction to water by the complex IV or cytochrome $c$ oxidase $(\mathrm{CcO})$, and ATP synthesis by ATP synthase (17, 25, 105-108). Three parameters have been proposed as key in controlling cell respiration: mitochondrial membrane $\mathrm{pH}$ gradient $(\Delta \mathrm{pH}), \mathrm{O}_{2}$ concentration and [ferricytochrome c]/[ferrocytochrome c] ratio at the ETC (109). Arnold et al. (109) first reported that $\mathrm{CcO}$ subunits stability is mediated by cardiolipin and essential for the regulations. They found that high mitochondrial matrix ATP-to-ADP ratio has an allosteric feedback inhibition on the complex IV and cell respiration. However, partial or total inhibition of the respiratory chain is one of the main causes of production of mitochondrial reactive oxygen species (ROS) $(73,74)$ and of actively-promoting mitochondrial metabolic switch supporting tumor progression and metastasis (13). Interestingly, singlet oxygen is reported as the main ROS produced during OXPHOS in yeast and human healthy and cancer cells' mitochondria (110). Its high reactive potential causes protein and mitochondrial DNA (mtDNA) damages $(111,112)$. However, new findings support the idea of metabolic and signaling activities of a mitochondrial low dose of ${ }^{1} \mathrm{O}_{2}$ (113). Zhou et al. (113) triggered ${ }^{1} \mathrm{O}_{2}$ generation in HeLa cancer cell line by laser irradiation and showed increased mtDNA replication, which is also a marker of increased mitochondrial respiration. Interestingly enough, pioneering studies showed that fast electron transfer through eukaryotes and prokaryotes electron transfer chain (ETC) achieves high $\mathrm{O}_{2}$ affinity to $\mathrm{CcO}$ $(19,21)$. More recently, studies have depicted the most probable mechanism beyond $\mathrm{O}_{2}$ activation by $\mathrm{CcO}$ complex $(24,37)$. CcO ensures cell respiration by sustaining both protons translocation and $\mathrm{O}_{2}$ reduction to water molecules. $\mathrm{O}_{2}$ activation is catalyzed by the binuclear heme-copper active site in a catalytic cycle by addition of four electrons routed through ETC (Figure 6B). Full $\mathrm{O}_{2}$ reduction is coupled with four protons translocation though the inner mitochondrial membrane (IMM) as showed in Figure 1 (20). The complete $\mathrm{O}_{2}$ reduction cycle model has been well depicted by (23), and the mitochondrial membrane stability seems to be a key parameter in oxygen activation and ROS generation (114).

\section{Singlet Oxygen-Oriented Photodynamic Therapy}

Taking all the above, we here propose the development of a novel therapy targeting singlet oxygen using photodynamic techniques. The expected outcome is ${ }^{1} \mathrm{O}_{2}$ or other ROS-induced cancer cells apoptosis and tumor regression as nicely reported in recent studies by the mean of extracellular singlet oxygen generation $(115,116)$. To do so, we propose that photosensitizers such as methylene blue (MB), chlorophyll, and protoporphyrin could play an intermediary role in the electron decongestion of ETC by catalyzing the activation of ${ }^{3} \mathrm{O}_{2}$ into ${ }^{1} \mathrm{O}_{2}$ and thus promoting apoptosis by accumulation of ROS species (Figure 6B). All these photosensitizers could be highly excited with a light source at specific wave lengths. $\mathrm{MB}$ has a double application. It is used as a dye in the textile industry, as well as a medicine for its antimicrobial properties and also applied as an antidote during cyanide, inhibitor of the complex IV (CIV), poisoning, or in cases of methemoglobinemia (117). Therefore, when administered MB acts as a CIV in the reduction of dioxygen to the water molecules (118) (Figure 6B). This singlet oxygen-oriented photodynamic therapy (PDT) is thought as a mimicry to chemotherapies such as does animals with predators $(113,119,120)$. In addition, we propose that ${ }^{1} \mathrm{O}_{2}$ oriented PDT could increase sensitivity of tumor cells, specially the resistant and ones, to conventional therapies. Furthermore, our recent study in Chinese Hamster Ovary (CHO) cells supports this hypothesis. Indeed, we have reported that combination of $\mathrm{MB}$ and METABLOC reduced the Warburg effect in $\mathrm{CHO}$ and optimized monoclonal antibody $(\mathrm{mAB})$ production, which is a marker of an increased mitochondrial OXPHOS (121). Finally, we strongly believe there are experimental evidences that the resistance of tumor to conventional treatments may be overcome by targeting cancer cells' "Achilles' heel," the ROS accumulation, by introducing photosensitizers as "trojan horses."

\section{CONCLUSION}

Mitochondria are much more than just a factory for producing energy for the cell. It is a cornerstone between the three essential processes for maintaining the stability of a multicellular 


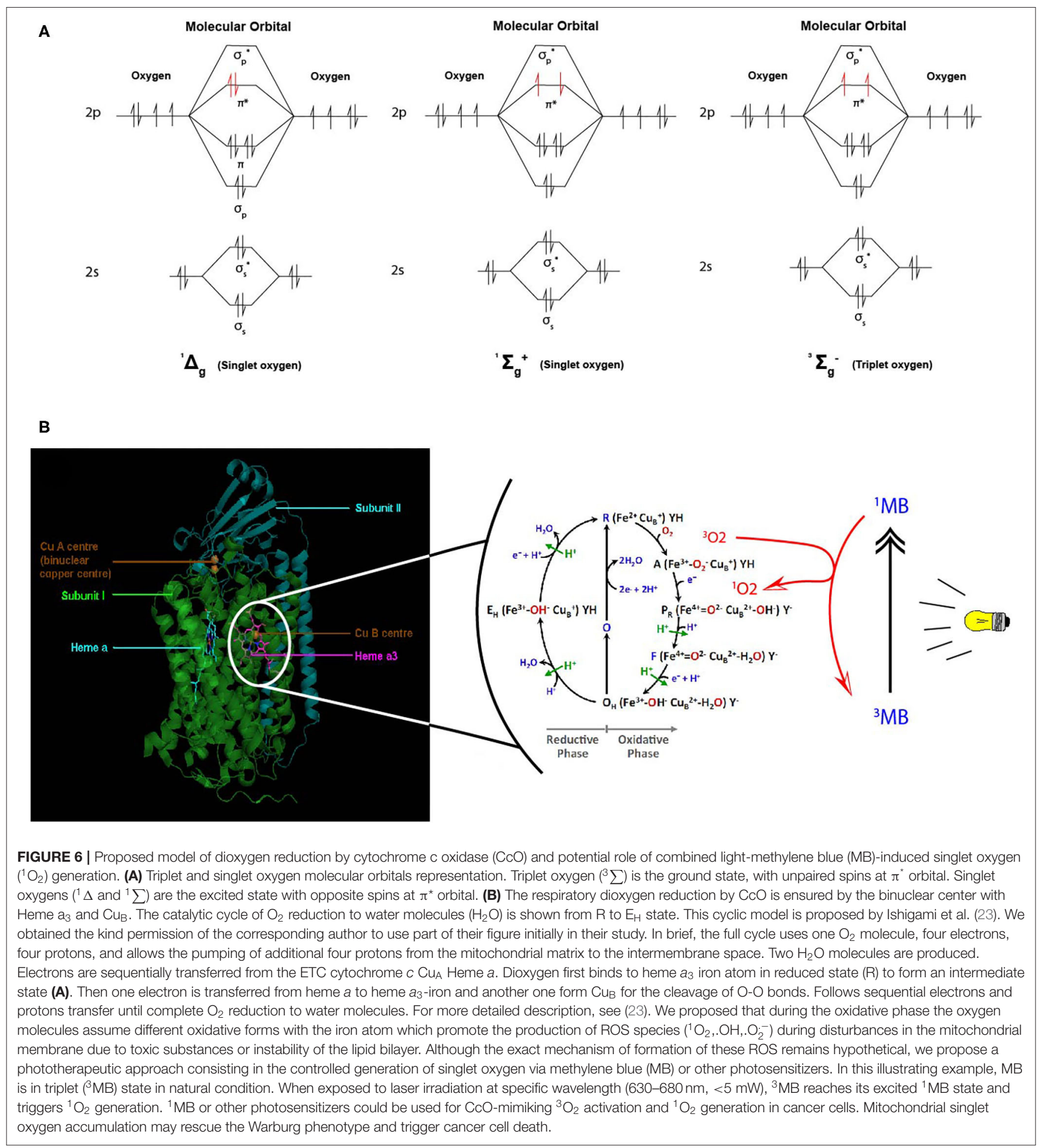

organism: proliferation, differentiation, and cell death. Poor regulation of asymmetric cell proliferation often leads to local destabilization of tissues and degenerates into tumor masses that escape all regulations by the immune system. Therapeutic approaches such as chemotherapies, metabolic therapies, immunotherapies, or even radiotherapy make it possible to eliminate the most fragile cancer cells. However, mitochondria confer the cells a great capacity for adaptation and resistance to these agents perceived as external stresses. Our proposals are a call to develop soft skills methods to hijack cancer cell metabolism. This involves the use of molecules easily ingested by cancer cells and perceived as beneficial to meet their energy 
demand. This is the case with photosensitizers like methylene blue, protoporphyrin or chlorophyll already implemented in plants. In the second step, one will be applying the photodynamic therapy in order to excite these molecules present in the cell. They will create highly reactive species of which singlet oxygen $\left({ }^{1} \mathrm{O}_{2}\right)$ seems to be the main produced at the level of the $\mathrm{CI}$, CIII, and perhaps CIV complexes of the ETC. We speculate that the accumulation of ${ }^{1} \mathrm{O}_{2}$ in mitochondria will trigger apoptosis in cancer cells, especially those that are resistant to conventional treatments.

\section{AUTHOR CONTRIBUTIONS}

JV wrote the manuscript and draw the figures. LS and MJ contributed to the thinking and reviewed the manuscript.

\section{REFERENCES}

1. Lane N. Oxygen: The Molecule That Made the World. (2003) Oxford, UK: Oxford University Press.

2. Blázquez-Castro A. Direct 102 optical excitation: a tool for redox biology. Redox Biol. (2017) 13:39-59. doi: 10.1016/j.redox.2017.05.011

3. Gonzalez H, Hagerling C, Werb Z. Roles of the immune system in cancer: from tumor initiation to metastatic progression. Genes Develop. (2018) 32:1267-84. doi: 10.1101/gad.314617.118

4. Keenan M, Chi J-T. Alternative fuels for cancer cells. Cancer J. (2015) 21:49-55. doi: 10.1097/PPO.0000000000000104

5. von Neumann J, Morgenstern O. Theory of Games and Economic Behavior. Princeton: Princeton University Press. (1944).

6. Smith JM, Maynard Smith J, Holliday R. Game theory and the evolution of behaviour. Proc R Soc Lond Series B Biol Sci. (1979) 205:475-88. doi: $10.1098 /$ rspb.1979.0080

7. DeBerardinis RJ, Chandel NS. We need to talk about the Warburg effect. Nat Metab. (2020) 2:127-9. doi: 10.1038/s42255-020-0172-2

8. Warburg O. On the origin of cancer cells. Science. (1956) 123:309-14. doi: 10.1126/science.123.3191.309

9. Warburg O. The metabolism of carcinoma cells. J Cancer Res. (1925) 9:14863. doi: $10.1158 /$ jcr.1925.148

10. Cassim S, Vučetić M, Ždralević M, Pouyssegur J. Warburg and beyond: the power of mitochondrial metabolism to collaborate or replace fermentative glycolysis in cancer. Cancers. (2020) 12:1119. doi: 10.3390/cancers12051119

11. Weinberg F, Chandel NS. Mitochondrial metabolism and cancer. Ann N Y Acad Sci. (2009) 1177:66-73. doi: 10.1111/j.1749-6632.2009.05039.x

12. Guerra F, Arbini AA, Moro L. Mitochondria and cancer chemoresistance. Biochim Et Biophys Acta Bioenerg. (2017) 1858:686-99. doi: 10.1016/j.bbabio.2017.01.012

13. Porporato PE, Payen VL, Pérez-Escuredo J, De Saedeleer CJ, Danhier P, Copetti T, et al. A mitochondrial switch promotes tumor metastasis. Cell Rep. (2014) 8:754-66. doi: 10.1016/j.celrep.2014.06.043

14. da Veiga Moreira J, Peres S, Steyaert J-M, Bigan E, Paulevé L, Nogueira ML, et al. Cell cycle progression is regulated by intertwined redox oscillators. Theor Biol Med Model. (2015) 12:10. doi: 10.1186/s12976-015-0005-2

15. Mitra K, Wunder C, Roysam B, Lin G, Lippincott-Schwartz J. A hyperfused mitochondrial state achieved at G1-S regulates cyclin E buildup and entry into S phase. Proc Natl Acad Sci USA. (2009) 106:11960-5. doi: 10.1073/pnas.0904875106

16. Weinberg SE, Sena LA, Chandel NS. Mitochondria in the regulation of innate and adaptive immunity. Immunity. (2015) 42:406-17. doi: 10.1016/j.immuni.2015.02.002

17. Mitchell P. Chemiosmotic coupling in oxidative and photosynthetic phosphorylation. Biol Rev. (1961) 41:445-501. doi: 10.1111/j.1469-185X.1966.tb01501.x
All authors contributed to the article and approved the submitted version.

\section{FUNDING}

This work has been supported by the French association Guérir du cancer empowered by Fondation de France and the Fondation et Alumni de Polytechnique Montréal.

\section{ACKNOWLEDGMENTS}

The authors thank Dr. Lyvia Blay for interesting discussions on chemoresistance.

18. Schultz BE, Chan SI. Structures and proton-pumping strategies of mitochondrial respiratory enzymes. Annu Rev Biophys Biomol Struct. (2001) 30:23-65. doi: 10.1146/annurev.biophys.30.1.23

19. Verkhovsky MI, Morgan JE, Puustinen A, Wikström M. Kinetic trapping of oxygen in cell respiration. Nature. (1996) 380:268-70. doi: 10.1038/380268a0

20. Wikström M, Sharma V. Proton pumping by cytochrome c oxidase - a 40 year anniversary. Biochim et Biophys Acta (BBA) - Bioenerg. (2018) 1859:692-8. doi: 10.1016/j.bbabio.2018.03.009

21. Wikstrom MKF. Proton pump coupled to cytochrome $c$ oxidase in mitochondria. Nature. (1977) 266:271-3. doi: 10.1038/266271a0

22. Tomashek JJ, Brusilow WS. Stoichiometry of energy coupling by protontranslocating ATPases: a history of variability. J Bioenerg Biomembr. (2000) 32:493-500. doi: 10.1023/A:1005617024904

23. Ishigami I, Lewis-Ballester A, Echelmeier A, Brehm G, Zatsepin NA, Grant TD, et al. Snapshot of an oxygen intermediate in the catalytic reaction of cytochrome c oxidase. Proc Natl Acad Sci USA. (2019) 116:3572-7. doi: $10.1073 /$ pnas. 1814526116

24. Wikström M, Krab K, Sharma V. Oxygen activation and energy conservation by Cytochrome c oxidase. Chem Rev. (2018) 118:2469-90. doi: 10.1021/acs.chemrev.7b00664

25. Mazat J-P, Ransac S, Heiske M, Devin A, Rigoulet M. Mitochondrial energetic metabolism—some general principles. IUBMB Life. (2013) 65:1719. doi: 10.1002/iub.1138

26. Heinrich R, Rapoport TA. A linear steady-state treatment of enzymatic chains. general properties, control and effector strength. Eur J Biochem. (1974) 42:89-95. doi: 10.1111/j.1432-1033.1974.tb03318.x

27. Kacser H, Burns JA. The control of flux. Biochem Soc Trans. (1995) 23:34166. doi: 10.1042/bst0230341

28. Reder C. Metabolic control theory: a structural approach. J Theor Biol. (1988) 135:175-201. doi: 10.1016/S0022-5193(88)80073-0

29. Bohnensack R, Küster U, Letko G. Rate-controlling steps of oxidative phosphorylation in rat liver mitochondria. a synoptic approach of model and experiment. Biochim Et Biophys Acta. (1982) 680:271-80. doi: 10.1016/0005-2728(82)90139-6

30. Kholodenko BN. Control of mitochondrial oxidative phosphorylation. $J$ Theor Biol. (1984) 107:179-88. doi: 10.1016/S0022-5193(84)80020-X

31. Rieske JS, MacLennan DH, Coleman R. Isolation and properties of an ironprotein from the (reduced coenzyme Q)-cytochrome C reductase complex of the respiratory chain. Biochem Biophys Res Commun. (1964) 15:338-44. doi: 10.1016/0006-291X(64)90171-8

32. Cecchini G. Function and structure of Complex II of the respiratory chain. Annu Rev Biochem. (2003) 72:77-109. doi: 10.1146/annurev.biochem.72.121801.161700

33. Sazanov LA, Hinchliffe P. Structure of the hydrophilic domain of respiratory complex I from thermus thermophilus. Science. (2006) 311:14306. doi: $10.1126 /$ science. 1123809 
34. Lauble H, Kennedy MC, Beinert H, Stout CD. Crystal structures of aconitase with isocitrate and nitroisocitrate bound. Biochemistry. (1992) 31:2735-48. doi: 10.1021/bi00125a014

35. Graham LA, Trumpower BL. Mutational analysis of the mitochondrial Rieske iron-sulfur protein of Saccharomyces cerevisiae. III. import, protease processing, and assembly into the cytochrome bcl complex of iron-sulfur protein lacking the iron-sulfur cluster. J Biol Chem. (1991) 266:22485-92.

36. Diaz F, Kotarsky H, Fellman V, Moraes CT. Mitochondrial disorders caused by mutations in respiratory chain assembly factors. Semin Fetal Neonatal Med. (2011) 16:197-204. doi: 10.1016/j.siny.2011.05.004

37. Wikström M, Sharma V. Oxygen reduction and proton translocation by respiratory Cytochrome c Oxidase. In: M. Ikeda-Saito, E. Raven, editors. Dioxygen-Dependent Heme Enzymes. Cambridge: Royal Society of Chemistry (2018). p. 311-33. doi: 10.1039/9781788012911-00311

38. Schäfer E, Seelert H, Reifschneider NH, Krause F, Dencher NA, Vonck J. Architecture of active mammalian respiratory chain supercomplexes. J Biol Chem. (2006) 281:15370-5. doi: 10.1074/jbc.M513525200

39. Chen D, Roda JM, Marsh CB, Eubank TD, Friedman A. Hypoxia inducible factors-mediated inhibition of cancer by GM-CSF: a mathematical model. Bull Math Biol. (2012) 74:2752-77. doi: 10.1007/s11538-012-9776-3

40. Strogolova V, Furness A, Robb-McGrath M, Garlich J, Stuart RA. Rcf1 and Rcf2, members of the hypoxia-induced Gene 1 protein family, are critical components of the mitochondrial Cytochrome bc1-Cytochrome c oxidase supercomplex. Mol Cell Biol. (2012) 32:1363-73. doi: 10.1128/MCB. 06369-11

41. Lenaz G, Genova ML. Supramolecular organisation of the mitochondrial respiratory chain: a new challenge for the mechanism and control of oxidative phosphorylation. In: Kadenbach B, editor. Mitochondrial Oxidative Phosphorylation: Nuclear-Encoded Genes, Enzyme Regulation, and Pathophysiology. New York, NY: Springer (2012). p. 107-44. doi: 10.1007/978-1-4614-3573-0_5

42. Vartak R, Porras CA-M, Bai Y. Respiratory supercomplexes: structure, function and assembly. Protein Cell. (2013) 4:582-90. doi: 10.1007/s13238-013-3032-y

43. DeBerardinis RJ, Lum JJ, Hatzivassiliou G, Thompson CB. The biology of cancer: metabolic reprogramming fuels cell growth and proliferation. Cell Metab. (2008) 7:11-20. doi: 10.1016/j.cmet.2007.10.002

44. DeBerardinis RJ, Chandel NS. Fundamentals of cancer metabolism. Sci Adv. (2016) 2:e1600200. doi: 10.1126/sciadv.1600200

45. Faubert B, Solmonson A, DeBerardinis RJ. Metabolic reprogramming and cancer progression. Science. (2020) 368:eaaw5473. doi: 10.1126/science.aaw5473

46. Lapuente-Brun E, Moreno-Loshuertos R, Acín-Pérez R, LatorrePellicer A, Colás C, Balsa E, et al. Supercomplex assembly determines electron flux in the mitochondrial electron transport chain. Science. (2013) 340:1567-70. doi: 10.1126/science.123 0381

47. McGuire WP, Hoskins WJ, Brady MF, Kucera PR, Partridge EE, Look KY, et al. Cyclophosphamide and cisplatin compared with paclitaxel and cisplatin in patients with Stage III and Stage IV ovarian cancer. N Engl J Med. (1996) 334:1-6. doi: 10.1056/NEJM199601043340101

48. Piccart MJ, Green JA, Lacave AJ, Reed N, Vergote I, Benedetti-Panici P, et al. Oxaliplatin or paclitaxel in patients with platinum-pretreated advanced ovarian cancer: a randomized Phase II study of the european organization for research and treatment of cancer gynecology group. J Clin Oncol. (2000) 18:1193-202. doi: 10.1200/JCO.2000.18.6.1193

49. Rosenberg B, Camp LV, Krigas T. Inhibition of cell division in Escherichia coli by electrolysis products from a platinum electrode. Nature. (1965) 205:698-9. doi: 10.1038/205698a0

50. Rosenberg B, Vancamp L, Trosko JE, Mansour VH. Platinum compounds: a new class of potent antitumour agents. Nature. (1969) 222:385-6. doi: $10.1038 / 222385 \mathrm{a} 0$

51. Rosenberg B, VanCamp L. The successful regression of large solid sarcoma 180 tumors by platinum compounds. Cancer Res. (1970) 30:1799-802.

52. Higby DJ, Higby DJ, Wallace HJ, Albert DJ, Holland JF. Diaminodichloroplatinum: a phase I study showing responses in testicular and other tumors. Cancer. (1974) 33:1219-25. doi: 10.1002/1097-0142 (197405)33:5\&lt;1219::AID-CNCR2820330505\&gt;3.0.CO;2-U
53. Ishida S, Lee J, Thiele DJ, Herskowitz I. Uptake of the anticancer drug cisplatin mediated by the copper transporter Ctr1 in yeast and mammals. Proc Natl Acad Sci USA. (2002) 99:14298-302. doi: 10.1073/pnas.162491399

54. Martinho N, Santos TCB, Florindo HF, Silva LC. Cisplatin-membrane interactions and their influence on platinum complexes activity and toxicity. Front Physiol. (2018) 9:1898. doi: 10.3389/fphys.2018.01898

55. Fuertes MA, Castilla J, Alonso C, Pérez JM. Cisplatin biochemical mechanism of action: from cytotoxicity to induction of cell death through interconnections between apoptotic and necrotic pathways. Curr Med Chem. (2003) 10:257-66. doi: 10.2174/0929867033368484

56. Stewart AL, Teno J, Patrick DL, Lynn J. The concept of quality of life of dying persons in the context of health care. J Pain Symptom Manage. (1999) 17:93-108. doi: 10.1016/S0885-3924(98)00131-6

57. Bishop JF, Dewar J, Toner GC, Smith J, Tattersall MH, Olver IN, et al. Initial paclitaxel improves outcome compared with CMFP combination chemotherapy as front-line therapy in untreated metastatic breast cancer. $J$ Clin Oncol. (1999) 17:2355-64. doi: 10.1200/JCO.1999.17.8.2355

58. Jordan MA, Wilson L. Microtubules as a target for anticancer drugs. Nat Rev Cancer. (2004) 4:253-65. doi: 10.1038/nrc1317

59. Orr GA, Verdier-Pinard P, McDaid H, Horwitz SB. Mechanisms of taxol resistance related to microtubules. Oncogene. (2003) 22:7280-95. doi: 10.1038/sj.onc.1206934

60. Rao S, Krauss NE, Heerding JM, Swindell CS, Ringel I, Orr GA, et al. 3'-(p-azidobenzamido)taxol photolabels the N-terminal 31 amino acids of beta-tubulin. J Biol Chem. (1994) 269:3132-4.

61. Banerjee S, Kaye SB. New strategies in the treatment of ovarian cancer: current clinical perspectives and future potential. Clin Cancer Res. (2013) 19:961-8. doi: 10.1158/1078-0432.CCR-12-2243

62. Boussiotis VA, Charest A. Immunotherapies for malignant glioma. Oncogene. (2018) 37:1121-41. doi: 10.1038/s41388-017-0024-Z

63. Davis A, Tinker AV, Friedlander M. "Platinum resistant" ovarian cancer: what is it, who to treat and how to measure benefit? Gynecol Oncol. (2014) 133:624-31. doi: 10.1016/j.ygyno.2014.02.038

64. Emmons MF, Faião-Flores F, Smalley KSM. The role of phenotypic plasticity in the escape of cancer cells from targeted therapy. Biochem Pharmacol. (2016) 122:1-9. doi: 10.1016/j.bcp.2016.06.014

65. Lorenzi T, Chisholm RH, Clairambault J. Tracking the evolution of cancer cell populations through the mathematical lens of phenotypestructured equations. Biol Direct. (2016) 11:43. doi: 10.1186/s13062-0160143-4

66. Hanahan D, Weinberg RA. The hallmarks of cancer. Cell. (2000) 100:57-70. doi: 10.1016/S0092-8674(00)81683-9

67. Hanahan D, Weinberg RA. Hallmarks of cancer: the next generation. Cell. (2011) 144:646-74. doi: 10.1016/j.cell.2011.02.013

68. Galluzzi L, Vacchelli E, Pedro J-MB-S, Buqué A, Senovilla L, Baracco EE, et al. Classification of current anticancer immunotherapies. Oncotarget. (2014) 5:12472-508. doi: 10.18632/oncotarget.2998

69. Samimi G, Varki NM, Wilczynski S, Safaei R, Alberts DS, Howell SB. Increase in expression of the copper transporter ATP7A during platinum drug-based treatment is associated with poor survival in ovarian cancer patients. Clin Cancer Res. (2003) 9:5853-9.

70. Bansal A, Simon MC. Glutathione metabolism in cancer progression and treatment resistance. J Cell Biol. (2018) 217:2291-8. doi: $10.1083 /$ jcb. 201804161

71. Hanigan MH. Gamma-glutamyl transpeptidase: redox regulation and drug resistance. Adv Cancer Res. (2014) 122:103-41. doi: 10.1016/B978-0-12-420117-0.00003-7

72. Nunes SC, Serpa J. Glutathione in ovarian cancer: a double-edged sword. Int J Mol Sci. (2018) 19:E1882. doi: 10.3390/ijms19071882

73. Sullivan LB, Chandel NS. Mitochondrial reactive oxygen species and cancer. Cancer Metab. (2014) 2:17. doi: 10.1186/2049-3002-2-17

74. Payen VL, Zampieri LX, Porporato PE, Sonveaux P. Pro- and antitumor effects of mitochondrial reactive oxygen species. Cancer Metastasis Rev. (2019) 38:189-203. doi: 10.1007/s10555-019-09789-2

75. Oliva CR, Moellering DR, Gillespie GY, Griguer CE. Acquisition of chemoresistance in gliomas is associated with increased mitochondrial coupling and decreased ROS production. PLoS ONE. (2011) 6:e24665. doi: 10.1371 /journal.pone. 0024665 
76. Oliva CR, Nozell SE, Diers A, McClugage SG, Sarkaria JN, Markert JM, et al. Acquisition of temozolomide chemoresistance in gliomas leads to remodeling of mitochondrial electron transport chain. J Biol Chem. (2010) 285:39759-67. doi: 10.1074/jbc.M110.147504

77. Hahn A, Zuryn S. Mitochondrial genome (mtDNA) mutations that generate reactive oxygen species. Antioxidants. (2019) 8:392. doi: 10.3390/antiox8090392

78. Gammage PA, Frezza C. Mitochondrial DNA: the overlooked oncogenome? BMC Biol. (2019) 17:53. doi: 10.1186/s12915-019-0668-y

79. Ishikawa K, Takenaga K, Akimoto M, Koshikawa N, Yamaguchi A, Imanishi $\mathrm{H}$, et al. ROS-generating mitochondrial DNA mutations can regulate tumor cell metastasis. Science. (2008) 320:661-4. doi: 10.1126/science.1156906

80. Warburg O, Wind F, Negelein E. The metabolism of tumors in the body. $J$ Gen Physiol. (1927) 8:519-30. doi: 10.1085/jgp.8.6.519

81. da Veiga Moreira J, Hamraz M, Abolhassani M, Bigan E, Pérès S, Paulevé L, et al. The redox status of cancer cells supports mechanisms behind the warburg effect. Metabolites. (2016) 6:33. doi: 10.3390/metabo6040033

82. Schwartz L, Abolhassani M, Guais A, Sanders E, Steyaert J-M, Campion F, et al. A combination of alpha lipoic acid and calcium hydroxycitrate is efficient against mouse cancer models: preliminary results. Oncol Rep. (2010) 23:1407-16. doi: 10.3892/or_00000778

83. Schwartz L, Seyfried T, Alfarouk KO, Da Veiga Moreira J, Fais S. Out of Warburg effect: an effective cancer treatment targeting the tumor specific metabolism and dysregulated pH. Semin Cancer Biol. (2017) 43:134-8. doi: 10.1016/j.semcancer.2017.01.005

84. da Veiga Moreira J, Hamraz M, Abolhassani M, Schwartz L, Jolicœur M, Peres S. Metabolic therapies inhibit tumor growth in vivo and in silico. Sci Rep. (2019) 9:3153. doi: 10.1038/s41598-019-39109-1

85. Israel M. Comment on cancer metabolism and on the role of the endocrine pancreas. J Clin Med Res. (2014) 6:490-1. doi: 10.14740/jocmr1912w

86. Israël M, Schwartz L. The metabolic advantage of tumor cells. Mol Cancer. (2011) 10:70. doi: 10.1186/1476-4598-10-70

87. Contractor T, Harris CR. P53 negatively regulates transcription of the pyruvate dehydrogenase kinase Pdk2. Cancer Res. (2012) 72:560-7. doi: 10.1158/0008-5472.CAN-11-1215

88. Dunford EC, Herbst EA, Jeoung NH, Gittings W, Greig Inglis J, Vandenboom $\mathrm{R}$, et al. $\mathrm{PDH}$ activation during in vitro muscle contractions in PDH kinase 2 knockout mice: effect of PDH kinase 1 compensation. Am J Physiol Regul Integr Comp Physiol. (2011) 300:R1487-R1493. doi: 10.1152/ajpregu.00498.2010

89. Sutendra G, Dromparis P, Kinnaird A, Stenson TH, Haromy A, Parker JMR, et al. Mitochondrial activation by inhibition of PDKII suppresses HIFla signaling and angiogenesis in cancer. Oncogene. (2013) 32:1638-50. doi: 10.1038/onc.2012.198

90. Michelakis ED, Webster L, Mackey JR. Dichloroacetate (DCA) as a potential metabolic-targeting therapy for cancer. Br J Cancer. (2008) 99:989-94. doi: 10.1038/sj.bjc.6604554

91. Sun H, Zhu A, Zhou X, Wang F. Suppression of pyruvate dehydrogenase kinase-2 re-sensitizes paclitaxel-resistant human lung cancer cells to paclitaxel. Oncotarget. (2017) 8:52642-50. doi: 10.18632/oncotarget.16991

92. Hu J, Komakula A, Fraser ME. Binding of hydroxycitrate to human ATP-citrate lyase. Acta Crystallogr D Struct Biol. (2017) 73:660-71. doi: 10.1107/S2059798317009871

93. Khwairakpam AD, Banik K, Girisa S, Shabnam B, Shakibaei M, Fan L, et al. The vital role of ATP citrate lyase in chronic diseases. J Mol Med. (2020) 98:71-95. doi: 10.1007/s00109-019-01 863-0

94. Viollet B, Guigas B, Sanz Garcia N, Leclerc J, Foretz M, Andreelli F. Cellular and molecular mechanisms of metformin: an overview. Clin Sci. (2012) 122:253-70. doi: 10.1042/CS20110386

95. Arrondeau J, Bost F. Metformine et aspirine: De $\ll$ nouveaux $\gg$ traitements du cancer? Oncologie. (2013) 15:480-9. doi: 10.1007/s10269-013-2319-1

96. Bodmer M, Meier C, Krähenbühl S, Jick SS, Meier CR. Long-term metformin use is associated with decreased risk of breast cancer. Diabetes Care. (2010) 33:1304-8. doi: 10.2337/dc09-1791

97. Evans JMM, Donnelly LA, Emslie-Smith AM, Alessi DR, Morris AD. Metformin and reduced risk of cancer in diabetic patients. BMJ. (2005) 330:1304-5. doi: 10.1136/bmj.38415.708634.F7
98. Al-Nimer MSM, Hameed HG, Mahmood MM. Antiproliferative effects of aspirin and diclofenac against the growth of cancer and fibroblast cells: in vitro comparative study. Saudi Pharm J. (2015) 23:483-6. doi: 10.1016/j.jsps.2015.01.002

99. Mayorek N, Naftali-Shani N, Grunewald M. Diclofenac inhibits tumor growth in a murine model of pancreatic cancer by modulation of VEGF levels and arginase activity. PLoS ONE. (2010) 5:e12715. doi: 10.1371/journal.pone.0012715

100. Weiss HM. Appreciating oxygen. J Chem Educ. (2008) 85:1218. doi: 10.1021/ed085p1218

101. Martin HD, Ruck C, Schmidt M, Sell S, Beutner S, Mayer B, et al. Chemistry of carotenoid oxidation and free radical reactions. Pure Appl Chem. (1999) 71:2253-62. doi: 10.1351/pac199971122253

102. Krieger-Liszkay A. Singlet oxygen production in photosynthesis. J Exp Bot. (2005) 56:337-46. doi: 10.1093/jxb/erh237

103. Krieger-Liszkay A, Fufezan C, Trebst A. Singlet oxygen production in photosystem II and related protection mechanism. Photosynth Res. (2008) 98:551-64. doi: 10.1007/s11120-008-9349-3

104. Suh H-J, Kim CS, Jung J. Cytochrome b6/f complex as an indigenous photodynamic generator of singlet oxygen in thylakoid membranes. Photochem Photobiol. (1999) 71:103-9. doi: 10.1562/0031-8655(2000)0710103CBFCAA2.0.CO2

105. Gennis RB. Coupled proton and electron transfer reactions in cytochrome oxidase. Front Biosci. (2004) 9:581-91. doi: 10.2741/1237

106. Lane N, Martin WF. The origin of membrane bioenergetics. Cell. (2012) 151:1406-16. doi: 10.1016/j.cell.2012.11.050

107. Wolf DM, Segawa M, Kondadi AK, Anand R, Bailey ST, Reichert AS, et al. Individual cristae within the same mitochondrion display different membrane potentials and are functionally independent. EMBO J. (2019) 38:e101056. doi: 10.15252/embj.201810 1056

108. Zorova LD, Popkov VA, Plotnikov EY, Silachev DN, Pevzner IB, Jankauskas SS, et al. Mitochondrial membrane potential. Anal Biochem. (2018) 552:50-9. doi: 10.1016/j.ab.2017.07.009

109. Arnold S, Kadenbach B. Cell respiration is controlled by ATP, an allosteric inhibitor of cytochrome-c oxidase. Eur J Biochem. (1997) 249:350-4. doi: 10.1111/j.1432-1033.1997.t01-1-00350.x

110. Wojtovich AP, Foster TH. Optogenetic control of ROS production. Redox Biol. (2014) 2:368-76. doi: 10.1016/j.redox.2014.01.019

111. Agnez-Lima LF, Melo JTA, Silva AE, Oliveira AHS, Timoteo ARS, Lima-Bessa KM, et al. DNA damage by singlet oxygen and cellular protective mechanisms. Mutat Res Rev Mutat Res. (2012) 751:15-28. doi: 10.1016/j.mrrev.2011.12.005

112. Sparsa A, Bellaton S, Naves T, Jauberteau M-O, Bonnetblanc J-M, Sol V, et al. Photodynamic treatment induces cell death by apoptosis or autophagy depending on the melanin content in two B16 melanoma cell lines. Oncol Rep. (2013) 29:1196-200. doi: 10.3892/or.2012.2190

113. Zhou X, Wang Y, Si J, Zhou R, Gan L, Di C, et al. Laser controlled singlet oxygen generation in mitochondria to promote mitochondrial DNA replication in vitro. Sci Rep. (2015) 5:16925. doi: 10.1038/srep16925

114. Hernansanz-Agustín P, Choya-Foces C, Carregal-Romero S, Ramos E, Oliva T, Villa-Piña $\mathrm{T}$, et al. $\mathrm{Na}+$ controls hypoxic signalling by the mitochondrial respiratory chain. Nature. (2020) 1-5. doi: 10.1038/s41586-020-2551-y

115. Bauer G, Sersenová D, Graves DB, Machala Z. Cold atmospheric plasma and plasma-activated medium trigger RONS-based tumor cell apoptosis. Sci Rep. (2019) 9:14210. doi: 10.1038/s41598-019-50291-0

116. Riethmüller $\mathrm{M}$, Burger $\mathrm{N}$, Bauer $\mathrm{G}$. Singlet oxygen treatment of tumor cells triggers extracellular singlet oxygen generation, catalase inactivation and reactivation of intercellular apoptosis-inducing signaling. Redox Biol. (2015) 6:157-68. doi: 10.1016/j.redox.2015.0 7.006

117. Ahmad I, Aqil F. New Strategies Combating Bacterial Infection. Hoboken, US: John Wiley \& Sons (2008). doi: 10.1002/9783527622931

118. Yang S-H, Li W, Sumien N, Forster M, Simpkins JW, Liu R. Alternative mitochondrial electron transfer for the treatment of neurodegenerative diseases and cancers: Methylene blue connects the dots. Prog Neurobiol. (2017) 157:273-91. doi: 10.1016/j.pneurobio.2015.1 0.005 
119. Kramarenko GG, Hummel SG, Martin SM, Buettner GR. Ascorbate reacts with singlet oxygen to produce hydrogen peroxide. Photochem Photobiol. (2006) 82:1634-7. doi: 10.1111/j.1751-1097.2006.tb09823.x

120. Yano S, Hirohara S, Obata M, Hagiya Y, Ogura S, Ikeda A, et al. Current states and future views in photodynamic therapy. J Photochem Photobiol C. (2011) 12:46-67. doi: 10.1016/j.jphotochemrev.2011.06.001

121. Montégut L, Martínez-Basilio PC, Moreira JV, Schwartz L, Jolicoeur M. Combining lipoic acid to methylene blue reduces the Warburg effect in CHO cells: From TCA cycle activation to enhancing monoclonal antibody production. PLoS ONE. (2020) 15:e0231770. doi: 10.1371/journal.pone.0231770
Conflict of Interest: The authors declare that the research was conducted in the absence of any commercial or financial relationships that could be construed as a potential conflict of interest.

Copyright $(\odot 2020$ da Veiga Moreira, Schwartz and Jolicoeur. This is an open-access article distributed under the terms of the Creative Commons Attribution License (CC $B Y)$. The use, distribution or reproduction in other forums is permitted, provided the original author(s) and the copyright owner(s) are credited and that the original publication in this journal is cited, in accordance with accepted academic practice. No use, distribution or reproduction is permitted which does not comply with these terms. 